\title{
A case of amnesia after excision of the septum pellucidum
}

\author{
A Berti, C Arienta, C Papagno
}

\begin{abstract}
Tumours of the septum pellucidum (SP) are rare and seldom associated with memory impairment either before or after operation. A patient is described who developed amnesia after transcallosal excision of a tumour of the SP. Radiology did not show any major lesion of the brain areas traditionally associated with amnesia. Because septal nuclei could have been damaged during surgery their possible role in memory functions is discussed.
\end{abstract}

Tumours of the septum pellucidum are rare, ${ }^{12}$ and when they do not lead to compression of other brain structures probably cause no symptoms.

Memory disorders before operation have seldom been reported, ${ }^{12}$ are poorly described and then usually in association with more general impairment. ${ }^{2}$ There is little evidence of improvement of memory disorders after the excision of the tumour. ${ }^{1}$ Even more rare is the finding of memory impairment after the excision of a tumour of the septum pellucidum when there was no memory impairment before the operation. ${ }^{1}$ We describe a patient with a tumour of the septum pellucidum diagnosed by CT scan and MRI, without memory impairment before operation. The patient developed a Korsakoff-type syndrome after surgery that was performed by a transcallosal interfornicial approach. ${ }^{3}$ We discuss the anatomy of the lesion and the possible role of the septal nuclei in memory function.

\section{Case history}

In 1980 a 43 year old female school teacher had a generalised epileptic seizure. The neurological examination was normal. An EEG revealed the presence of an epileptogenic focus in the right fronto-temporal region. The patient was discharged on carbamazepine. In 1982 she reported a second generalised epileptic seizure. CT scan with and without contrast was normal. Carbamazepine was replaced by phenobarbital. In October 1987 she had a third generalised epileptic seizure and she was admitted to the neurological department of our hospital. CT and MRI scans showed a marked hydrocephalus and a tumour of the septum pellucidum that enhanced with contrast.
Before surgery she did not complain of any subjective disorder and the neurological examination was completely normal. She did not show any neuropsychological deficit and her relatives claimed that she was carrying on an absolutely normal life.

On 27 January 1988 the patient had a surgical excision of the tumour via a right transcallosal approach. 'The tumour was welldelineated and easily cleavable, completely occupying the septum pellucidum. A vascular peduncle of the tumour was seen at its bottom and was disconnected with bipolar coagulation. Histology demonstrated a subependymoma.

Postoperative outcome was good. However, the peculiar behaviour of the patient was immediately obvious: she forgot everything she was told and names of new people, or why she was at a particular place and how long she had been there; she always asked if she had already performed some examination. She could not remember which day or what time of the day it was and kept talking about an abortion that she had had years ago. Sometimes she said that she was living as if in a dream and she was never sure whether she had seen people or places in real life or had dreamt of them. An MRI scan (fig 1a, 1b) showed an ischaemic lesion of the left cingulate gyrus.

\section{Neuropsychological assessment}

Two weeks after surgery the patient was alert and cooperative, but a memory impairment was immediately evident, because she kept asking the examiner the same questions (for example, "which day is it today?") and forgetting the answer a minute later. She was disoriented in time and place; only occasionally did she remember the year and, even if she knew which hospital she was in she was unable to remember the name of the ward and had some difficulties in finding her way around. She claimed that she had already been in the ward (which was true), but she could not remember when. Her name and date of birth could be remembered, but not her age and she remembered having two daughters and their names and ages. There was no severe confabulation except that she often said that the husband of the patient next to her was her boyfriend when they were young. Her score on Raven PM 38 was 32/36 (cut-off 18/ 36). There was no perceptual deficit when assessed by the Poppelreuter Test and a Per- 


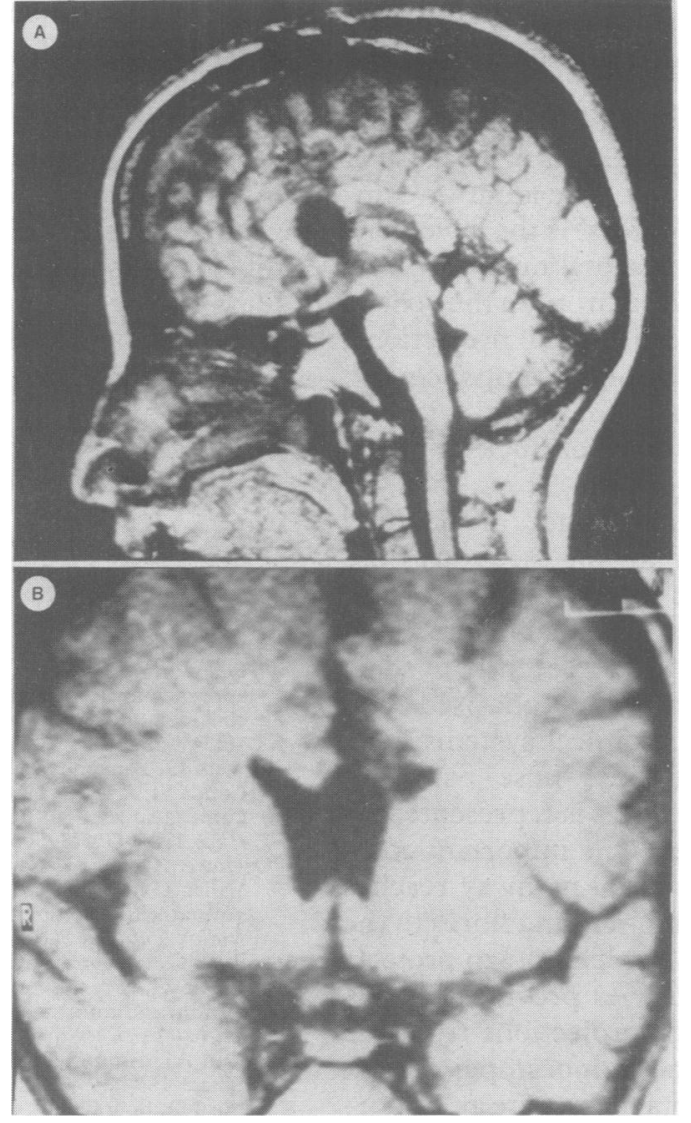

Figure 1 $a, b \quad M R I$ showing the consequences of the excision of septum pellucidum.

ceptual Categorisation Test. There were no signs of a callosal syndrome.

Frontal functions were assessed by means of the Wisconsin Card Sorting Test, which was absolutely normal (she completed 7 stages).

Language tests showed perfect Phonemic Discrimination (60/60), normal comprehension of isolated words (Peabody Picture Test: 66/70), Naming by Description (37, cutoff $>33.50$ ), Object Naming (31.75, cutoff $>28 \cdot 25) .{ }^{4}$ Wechsler Vocabulary (8), Syntactic Comprehension (74/80), and Sentence Comprehension (12/12) were also normal. Only Semantic Fluency was under the cut-off (14, cut-off > 25). ${ }^{4}$ It was impossible to perform the Token Test because the patient forgot the task immediately after the instructions.

Memory tests included Digit and Corsi

Table Memory tests after surgery

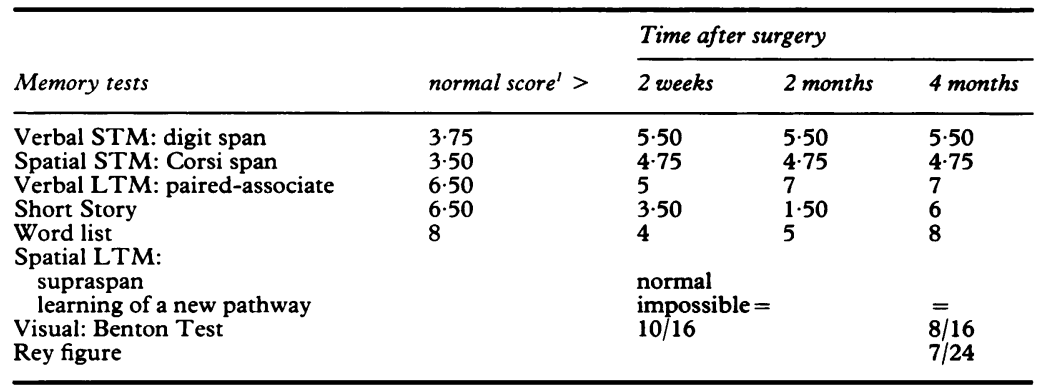

${ }^{1}$ The score of $95^{\circ}$ of 321 subjects was more than the value in this column. span for short-term memory (STM). ${ }^{5}$ Short Story, paired associate learning and word list learning ${ }^{6}$ for verbal long-term memory (LTM); supraspan learning of a new pathway for long-term spatial memory; Benton Test for visual memory. Results are shown in the table. Autobiographical memory was assessed by means of a questionnaire that included questions about life from childhood until the onset of the disease. She could not remember events which happened in the previous three months. When talking about her past she focused on two particular episodes of her life (a child living next to her who lost one eye in an accident, and her abortion) and it was very difficult to move her attention to other subjects such as school, marriage, or work.

Tests were repeated after two and four months and the patient did not show any improvement apart from paired-associate learning (table).

\section{Discussion}

Our patient showed the classic features of global amnesic syndrome: she was unable to acquire new information after surgery (anterograde amnesia) and to remember events which happened in the three months before surgery (retrograde amnesia). She also showed a mild confabulation and little concern about her memory impairment. STM, language and general intelligence were preserved.

Memory loss is usually described after grey matter damage of either the medial temporal lobe, medial thalamus and mamillary bodies. ${ }^{7}$

The patient developed amnesia after surgical excision of a tumour of SP made by a transcallosal interfornicial approach. This method has been reported to not affect memory function. ${ }^{3}$ Zaidel and Sperry ${ }^{8}$ reported ten commissurotomy patients who had subnormal scores on a battery of memory tests; they conclude that the loss of the cerbral commissures is mainly responsible for this impairment. However, the operative procedure involved the corpus callosum, and the hippocampal and anterior commissures, including the columns of the fornix. We do not exclude the possibility that the observed memory impairment could be amplified by extracommissural brain damage. Moreover, these patients have a mild disturbance, not a frank amnesic syndrome as in our patient.

Neuroradiological studies, in our case, did not show any convincing alteration of the brain areas traditionally associated with amnesia, but we cannot completely exclude that perioperative manipulation caused damage in some areas of the brain. For instance, in our patient there was a small infarct of the right cingulate gyrus. There is some evidence that major destruction of the anterior cingulate gyrus can transiently affect memory. ${ }^{9}$ There are a few cases of transient amnesia associated with damage to the fornices, but other structures could be altered as well. ${ }^{7}$ Apart from the case of Heilman and Sypert, ${ }^{10}$ in which the lesion involved the splenium and both pos- 
terior fornices, there is little certainty that lesions restricted to the fornices cause amnesia. $^{7}$

Another structure that could be damaged in our case (either by surgery itself or because of damage in the circulation of the anterior communicating artery perforators) is the lower part of the septal region. The septal nuclei are part of a cluster of cholinergic neurons in the ventral forebrain with widespread cortical projections, one of which reaches the hippocampal cortex. The septal nuclei are also connected with the amygdala and the dorsomedial nucleus of the thalamus.

Goldberg, ${ }^{11}$ noted that Papez proposed a circuit in which the following structures are sequentially arranged: hippocampus-fornixmamillary bodies-anterior thalamic nucleuscingulate gyrus. More recently some experimental studies have emphasised two separate but parallel anatomical systems. One is essentially composed by those pathways proposed by Papez, the other is represented by the amygdaloid system. ${ }^{12}$ One important component of the amygdalofugal pathway reaches rostrally the septal region, sending fibres to the dorsal medial thalamus, which in turn projects to the pre-frontal cortex. As previously mentioned, one of the major projections from the septal nuclei reaches the hippocampal cortex. This means that the septal nuclei are an important relay between the two systems. Memory problems therefore should be more severe either with combined lesions of the two systems ${ }^{12}$ or with one lesion to a structure involving both of them (for example, septal nuclei). Since the fornix, according to Goldberg's model, ${ }^{11}$ is an auxiliary component, being an interface between the two systems, the lesion of the fornix would be expected to have a relatively small effect on memory. This predic- tion seems to be supported by the existing evidence.

Alexander and Freedman had already pointed out the possibility that in patients with an anterior communicating artery rupture, the most important structures involved in producing amnesia are the septal nuclei. ${ }^{13}$ Because radiology, in our case, failed to show any major lesion of the other structures traditionally involved in memory function, we propose that at least in this case amnesia can be due to a lesion of septal nuclei, destroyed by the surgical excision of the septum pellucidum.

1 French JD, Bucy PC. Tumors of the septum pellucidum. Neurosurg 1948;5:433-49.

2 Bedou G, Caruel N, Pertuiset B. Tumeurs du septum lucidum. Rev Neurol 1927;127:341-53.

3 Apuzzo MLJ, Chikovani OK, Gott PS, Teng EL, Zee C Giannotta SL, Weiss MH. Transcallosal interfornicial approach for lesions affecting the third ventricle: surgical considerations and consequences. Neurosurgery 1982; 10:547-53.

4 Novelli G, Papagno C, Capitani E, Laiacona M, Vallar G, Cappa SF. Tre test clinici di ricerca e produzione lessicale: taratura su soggetti normali. Arch Ital di Neurol Psicol e Psich 1986;47:477-506.

5 Orsini A, Grossi D, Capitani E, Laiacona M, Papagno C, Vallar $G$. Verbal and spatial immediate memory span: normative data from 1355 adults and 1112 children. The normative data from 1355 adults and 1112 .
Italian $J$ of Neurol Sciences 1987;8:539-48.

6 Novelli G, Papagno C, Capitani E, Laiacona M, Cappa SF, Vallar $G$. Tre test clinici di memoria verbale a lungo termine: taratura su soggetti normali. Arch Ital di Neurol Psicol e Psich 1986;47:278-96.

7 Parkin AJ. Amnesic syndrome: a lesion-specific disorder? Cortex 1984;20:479-508.

8 Zaideal D, Sperry RW. Memory impairment after commissurotomy in man. Brain 1974;97:263-72.

9 Whitty CWM, Lewin W. A Korsakoff syndrome in the postcingulectomy confusional state. Brain 1960;83 648-53.

10 Heilman KM, Sypert GW. Korsakoff's syndrome resulting from bilateral fornix lesions. Neurology 1977;27:490-3.

11 Goldberg E. Papez circuit revisited: two systems instead of one. In: Squire L, Butters N, eds. Neuropsychology of one. In: Squire L, Butters N, eds. Neuropsychology
memory. New York: Guildford Press, 1984:183-93.

12 Miskin M. Memory in monkeys severely impaired by Miskin $M$. Memory in monkeys severely impaired by
combined but not by separate removal of amygdala and hippocampus. Nature 1978;273:297-8.

13 Alexander MPA, Freedman M. Amnesia after anterior communicating artery aneurysm rupture. Neurology (Cleveland) 1984;34:752-7. 